\title{
Endoscopic Transphenoidal Surgery for Acromegaly Improves Quality of Life
}

\author{
Hussein Fathalla, Michael D. Cusimano, Omar M. Alsharif, Rowan Jing
}

\begin{abstract}
Background: Acromegaly has important effects on quality of life (QOL). This is the first study to measure QOL in acromegalic patients after endoscopic transsphenoidal surgery (ETSS). Methods: We prospectively collected the RAND-36, Center for Epidemiologic Studies Depression (CES-D), and Pituitary QOL validated questionnaires and patients' demographics, clinical presentation, endocrine laboratory results, radiological studies, development of complications and remission rates from 20 consecutive acromegalic patients who had undergone endoscopic transphenoidal surgery. Results: The eleven females and nine males had an average age of 42 years; 90 percent had macroadenomas and $70 \%$ had cavernous sinus invasion on their preoperative imaging. Ninety percent had improved symptoms post-operatively and $80 \%$ stated that treatment improved their QOL. Biochemically, $35 \%$ were cured, $35 \%$ had discordant results and $30 \%$ were not cured, while pan-hypopituitarism occurred in 4 patients. Physical health subscales and pituitary-related symptoms were similar to norms. "Social," "emotional health," and "energy levels" were significantly lower than norms. Seventy percent stated that their relationship with their physician "very much so" affected their quality of life. Pan hypopituitarism and adjuvant therapy were the most significant predictors of lower QOL subscale scores. Conclusion: Transsphenoidal surgery improves QOL in acromegaly. Attempts to achieve a cure, avoidance of surgically induced pan-hypotpituitarism and adjuvant therapy, will improve quality of life. Our study demonstrates the important role of the patient-physician relationship to QOL and the need to measure QOL in addition to the traditional measures of outcome.
\end{abstract}

RÉSUMÉ: La chirurgie endoscopique transsphénö̈dale pour traiter l'acromégalie améliore la qualité de vie. Contexte: L'acromégalie a des répercussions importantes sur la qualité de vie $(\mathrm{QV})$. Cette étude est la première à mesurer la $\mathrm{QV}$ après une chirurgie endoscopique transsphénoïdale chez des patients atteints d'acromégalie. Méthode: Nous avons recueilli de façon prospective les scores aux questionnaires validés RAND-36, Center for Epidemiologic Studies Depression et Pituitary QOL et les données démographiques des patients, le mode de présentation clinique, les résultats de dosages endocriniens, les études radiologiques, les complications et les taux de rémission chez 20 patients acromégales consécutifs qui ont subi une chirurgie endoscopique transsphénoïdale. Résultats: Parmi les 11 femmes et 9 hommes, dont l'âge moyen était de 42 ans, $90 \%$ présentaient des macroadénomes et $70 \%$ présentaient une invasion du sinus caverneux à l'imagerie préopératoire. Chez $90 \%$ des patients les symptômes ont été atténués par la chirurgie et $80 \%$ affirmaient que le traitement avait amélioré leur QV. 35\% étaient guéris, 35\% présentaient des résultats discordants et 30\% n'étaient pas guéris. Quatre patients ont présenté un panhypopituitarisme. Les scores aux sous-échelles de santé physique et les symptômes en lien avec l'hypophyse étaient dans les limites normales. «La santé sociale » et « émotionnelle » et le « niveau d'énergie » étaient significativement inférieurs aux normes. Soixante-dix pour cent des patients ont déclaré que leur relation avec leur médecin influençait beaucoup leur qualité de vie. Le panhypopituitarisme et le traitement de remplacement prédisaient de façon significative des scores inférieurs à la sous-échelle de la QV. Conclusion: La chirurgie transsphénoïdale améliore la QV dans l'acromégalie. Tenter de guérir le patient, éviter le panhypopituitarisme causé par la chirurgie et administrer un traitement adjuvant améliore la qualité de vie des patients. Notre étude démontre l'influence importante de la relation patient-médecin sur la QV et la nécessité de mesurer la QV en plus des mesures traditionnelles de résultats.

Keywords: Acromegaly, quality of life, pit qol, endoscopic transphenoidal surgery, pituitary adenoma

doi:10.1017/cjn.2014.106

Can J Neurol Sci. 2014; 41: 735-741

Health related quality of life (HRQOL) describes an individual's perceived physical, mental and social well-being or distress and the ability to engage in daily functions. ${ }^{1}$ Instruments to measure HRQOL can be classified as "general" (such as the RAND-36) 2,3 or "disease specific" such as the Acromegaly quality of life instrument (AcroQoL) ${ }^{4}$ or the Pituitary Quality of Life instrument (Pit QOL). ${ }^{5}$

Acromegaly is a chronic disease with important effects on Quality of life (QOL), even after cure. ${ }^{6}$ Acromegaly or its treatment can affect body image, energy levels, self esteem, emotional stability, social interactions, and emotional state. ${ }^{7-10}$ Prior attempts to measure QOL in acromegaly are few. Badia et al. ${ }^{4}$ developed the AcroQoL instrument in 2001 in Spanish and although it provides useful information, its translation to English is a major limitation. A number of authors have used this scale to assess QOL in acromegalic patients ${ }^{11-14}$ and this contributed greatly to our understanding of this disease and the effect it has on our patients. What seems to be missing however, is studying the effect of endoscopic transsphenoid surgery (ETSS) on vision, social and emotional health, in addition to

From the Division of Neurosurgery (HF, MDC, OMA), University of Toronto; Keenan Research Centre (HF, MDC, OMA), Li Ka Shing Knowledge Institute, St. Michael's Hospital, Toronto, Ontario, Canada.

Received June 10, 2014. Final Revisions Submitted October 15, 2014.

Correspondence to: Michael Cusimano, St. Michael's Hospital, 30 Bond Street, Toronto, Ontario, M5B 1W8, Canada. E-mail: injuryprevention@smh.ca 
other QOL aspects that are commonly affected after surgery. We believe it is also important to determine the role that health professionals play in a patient's QOL.

The purpose of our study was to perform a comprehensive evaluation of QOL, using both general and disease specific measures, in acromegalic patients undergoing endoscopic transsphenoidal surgery. We also sought to explore the relationship of QOL scores to clinical outcomes such as clinical improvement, degree of tumor resection and biochemical remission.

\section{MethodS}

A series of 20 consecutive patients diagnosed with acromegaly were given a series of questionnaires as part of their routine postoperative follow-up. We documented patients' demographics, clinical presentation, laboratory results, full endocrine assessment preoperatively and on each follow up, radiological studies, treatment details, development of complications, degree of tumor resection on postoperative imaging and endocrine remission rates. All patients underwent ETSS, by our previously described technique, ${ }^{15}$ performed by a single surgeon, and all had pathologically proven growth hormone $(\mathrm{GH})$ pituitary adenomas.

Disease remission was defined according to the criteria of the 2010 Endocrine Society Consensus as: normal age- and sexadjusted (insulin-like growth factor 1) IGF-I levels and either a random $\mathrm{GH}$ of $<1.0 \mu \mathrm{g} / \mathrm{L}$ or $\mathrm{GH}$ nadir $<0.4 \mu \mathrm{g} / \mathrm{L}$ after an oral glucose tolerance test. ${ }^{16}$

The three validated questionnaires given to the patients were (a) the Quality of Life Questionnaire for Patients with Pituitary Tumour (PIT QOL); ${ }^{5}$ (b) RAND-36 -Item Health Survey (identical questions to MOS-SF36); ${ }^{2,17}$ c) Center for Epidemiologic Studies Depression (CES-D) Questionnaire. ${ }^{18-22}$ Norms (controls) for the PIT QOL were derived from 15 patients with asymptomatic, incidentally discovered microadenomas that are being followed up and didn't receive any treatment. These 15 patients filled the PIT QOL questionnaire and their scores were used as the norm. Norms for the RAND 36 (SF-36) were derived from the Canadian normative data of the SF- $36,{ }^{23}$ which is a huge Canadian study that provided norm scores of the general Canadian population in the RAND-36.

\section{a) Quality of Life Questionnaire for Patients with Pituitary Tumour (PIT QOL)}

This disease specific questionnaire with 53 questions rated on a 7 point Liekert. Higher scores represent higher quality of life. The scale was developed and validated by our senior author M.C in $2005,{ }^{8}$ specifically to measure quality of life of pituitary patients. The questionnaire has the following subscales:

1) General and Emotional (maximum score is 126): Eighteen questions about general health, energy, physical pain, ability to perform work, sex life, and emotional content (stress, anxiety, peacefulness, happiness and sense of accomplishment).

2) Social (maximum score is 56): Eight questions mainly on relationship with family, friends and support received.

3) Health Problems Related to Pituitary Disease (maximum score is 140): Twenty questions on symptoms of pituitary tumors such as hormonal imbalance (stretch marks, menstruation, size of tongue, features, weight gain, nipple discharge, etc.), vision, headache and personality changes.
4) Treatment Related (maximum score is 21): Three questions on how the treatment and its side effects affected the quality of life.

5) Relationship with Physician (maximum score is 28): Four questions to assess the relationship with the family doctor, endocrinologist and neurosurgeon and how these relationships affects patients QOL.

\section{b) RAND-36 -Item Health Survey}

This 36 items-survey is identical to the MOS SF-36 described in Ware and Sherbourne. ${ }^{2}$ The RAND-36, a general instrument for measuring health status in any generic population, can provide an estimate of the overall QOL of patients with pituitary tumors. ${ }^{17}$ The RAND 36-Item Health Survey (Version 1.0) covers eight concepts (Each has a maximum score of 100) and has a maximum total score of 800 :

1) physical functioning

2) bodily pain

3) role limitation due to physical health

4) role limitation due to emotional health

5) emotional well being

6) social functioning

7) energy/fatigue

8) general health perception

\section{c) CES-D Questionnaire}

The Center for Epidemiologic Studies Depression Scale (CES-D) is a validated and widely used measure of depression. ${ }^{18,19}$ The 20 item scale measures sadness, sleep, loss of interest, appetite, concentration, worthlessness, fatigue, agitation and suicidal thoughts. Scores higher than 16 indicated depressive illness. $^{18,19}$

\section{Statistical Analysis}

SPSS 20 software (SPSS Inc., Chicago, Illinois) was used for statistical analyses. Data were presented as mean \pm Standard Deviation (SD) for normal variables and medians and interquartile ranges (IQR) for skewed variables. Comparisons between groups were performed using $\mathrm{t}$ tests, Non-Parametric Tests (KruskalWallis), and Chi-Square tests depending on the distribution of variables. Pearson correlation coefficients are calculated to explore the relationship among variables. Pituitary QOL scores were evaluated by comparing them to the scores of the control group. RAND-36 scores were also evaluated by comparing them with their control norm group, but for easier analysis and demonstration, we used norm-based scoring for this comparison, i.e. all RAND-36 subscale scores for the control groups were set and recalculated as mean 50 and SD 10, then the scores of our study group recalculated and plotted against the control so that the relative amount of deviation from the norm remains the same in the new model.

\section{RESULTS}

\section{Patient Characteristics and QOL scores}

Table 1 summarizes our patients' characteristics. The mean period from the surgery to filling the questionnaires was 11 months 
(Range 8-13 months). Tables 2 and 3 summarize the scores of patients on the three questionnaires. The PIT QOL subscales entitled "Pituitary-Related" and the "Relationship With Physician "had higher scores than the norm. Subscale scores of "Social Health" and

Table 1: Patient characteristics and outcome.

\begin{tabular}{|c|c|c|c|c|}
\hline & Minimum & Maximum & Mean & SD \\
\hline Age(years) & 17 & 71 & 42 & 13.5 \\
\hline \multirow{2}{*}{$\begin{array}{l}\text { Follow up period } \\
\text { (months) }\end{array}$} & 8 & 13 & 11 & 3.1 \\
\hline & Minimum & Maximum & Median & $\begin{array}{c}\text { Interquartile } \\
\text { range }\end{array}$ \\
\hline Tumor volume & 0.1 & 20.8 & 3.8 & 2.4 \\
\hline Postop. Igf-1 (ng/mL) & 72.0 & 1290.0 & 305 & 228.8 \\
\hline \multirow[t]{2}{*}{ Postop. GH $(\mu \mathrm{g} / \mathrm{L})$} & 0.1 & 35.0 & 1.3 & 2.6 \\
\hline & Number & $\%$ & & \\
\hline \multicolumn{5}{|l|}{ Resection } \\
\hline Gross total resection & 10 & $50 \%$ & & \\
\hline Subtotal resection & 10 & $50 \%$ & & \\
\hline \multicolumn{5}{|l|}{ Adjuvant treatment } \\
\hline medical & 7 & $35 \%$ & & \\
\hline radiation & 1 & $5 \%$ & & \\
\hline Re-surgery & 5 & $25 \%$ & & \\
\hline Pituitary insufficiency & 4 & $20 \%$ & & \\
\hline \multicolumn{5}{|l|}{ Sex } \\
\hline male & 9 & $45 \%$ & & \\
\hline Female & 11 & $55 \%$ & & \\
\hline \multicolumn{5}{|l|}{ Knosp score } \\
\hline $0-2$ & 6 & $30 \%$ & & \\
\hline$>2$ & 14 & $70 \%$ & & \\
\hline \multicolumn{5}{|l|}{ Outcome } \\
\hline Remission & 7 & $35 \%$ & & \\
\hline $\begin{array}{l}\text { Discordant results } \\
\text { (either normal OGTT } \\
\text { or IGF-1) }\end{array}$ & 7 & $35 \%$ & & \\
\hline Non-cure & 6 & $30 \%$ & & \\
\hline
\end{tabular}

Postop $=$ post operative; IGF $-1=$ Insulin like Growth Factor 1; GH = Growth hormone; OGTT $=$ Oral Glucose Tolerance Test; $\mathrm{SD}=$ Standard Deviaton the "General And Emotional" were significantly lower than the norm. Figure 1 compares the median scores of PIT QOL subscales in relation to the norms. For CES-D, The median score was 10 (Range 0-44, Mean 11.3) denoting non-significant psychological impact of surgery. For the general QOL instrument, RAND-36, the highest scores compared to the Canadian norm, was for the "Physical Health" subscale and "Role Limitation Due To Emotional Aspect". The lowest scores were for the "Energy Levels" subscale. Figure 2 compares the median scores of our patients to Canadian norms on the RAND-36 subscales.

\section{Impact of ETSS on QOL}

Two questions specifically compared the QOL before and after surgery:

1. "Rate your satisfaction with the treatment in controlling your symptoms and improving your quality of life." Sixteen patients $(80 \%)$ admitted it was good to excellent, while four patients $(20 \%)$ answered that it was poor.

2. "Compared to before surgery, how would you rate your general health now?" Fourteen patients (70\%) admitted it was better, four patients $(20 \%)$ admitted it was the same, and two patients $(10 \%)$ said it was worse.

\section{Impact of clinical, endocrine and radiological outcomes on QOL}

We studied the association of different variables on the scores in all questionnaires. There was no significant effect of endocrine remission, gross total resection, preoperative tumor volume, cavernous sinus invasion or repeated surgery on any of the QOL total or subscale scores.

Patients who developed pan-hypopituitarism had significantly worse total CES-D scores and total RAND-36 scores (Figure 3) than those with normal postoperative pituitary function ( $\mathrm{p} 0.03$ and 0.02 respectively). The RAND36 (SOCIAL) and RAND-36 (PAIN) subscale scores were also worse in this subset of patients (Table 4); P0.02 and P0.007 respectively. Patients who were on adjuvant therapy (with somatostatin analogues) or had radiation at the time of their questionnaires had significantly worse total CESD and RAND-36 scores (Figure 3) than patients who didn't receive adjuvant treatment ( $\mathrm{p} 0.005$ and $\mathrm{p} 0.02$ respectively). There was also significant reduction in the scores of the RAND-36 (PHYSICAL), RAND-36(EMOTIONAL), RAND-36(SOCIAL) and RAND-36 (PAIN) subscales (p 0.008, p 0.02, p 0.03 and p 0.05 respectively) (see Table 4 ).

Table 2: Patients' scores on the PIT QOL and CES-D.

\begin{tabular}{|c|c|c|c|c|c|c|c|}
\hline & $\begin{array}{c}\text { PIT QOL } \\
\text { general }\end{array}$ & $\begin{array}{l}\text { PIT QOL } \\
\text { social }\end{array}$ & $\begin{array}{l}\text { PIT QOL pituitary } \\
\text { related }\end{array}$ & $\begin{array}{c}\text { PIT QOL treatment } \\
\text { related }\end{array}$ & $\begin{array}{c}\text { PIT QOL relationship with } \\
\text { physician }\end{array}$ & $\begin{array}{l}\text { PIT QOL } \\
\text { Total }\end{array}$ & $\begin{array}{l}\text { CES- } \\
\text { D }\end{array}$ \\
\hline Minimum & 53 & 23 & 91 & 5 & 16 & 210 & 0 \\
\hline Maximum & 122 & 56 & 140 & 21 & 28 & 364 & 44 \\
\hline Mean & 88.5 & 39.5 & 112.4 & 14 & 23.4 & 276.7 & 14 \\
\hline SD & 19.4 & 8.5 & 13.2 & 5.6 & 23 & 38.6 & 11.3 \\
\hline Median & 91 & 39.5 & 113 & 14.5 & 24 & 271.5 & 10 \\
\hline
\end{tabular}

PIT QOL = pituitary Quality of life; CES-D = Center for Epidemiologic Studies-Depression; SD = Standard Deviation 

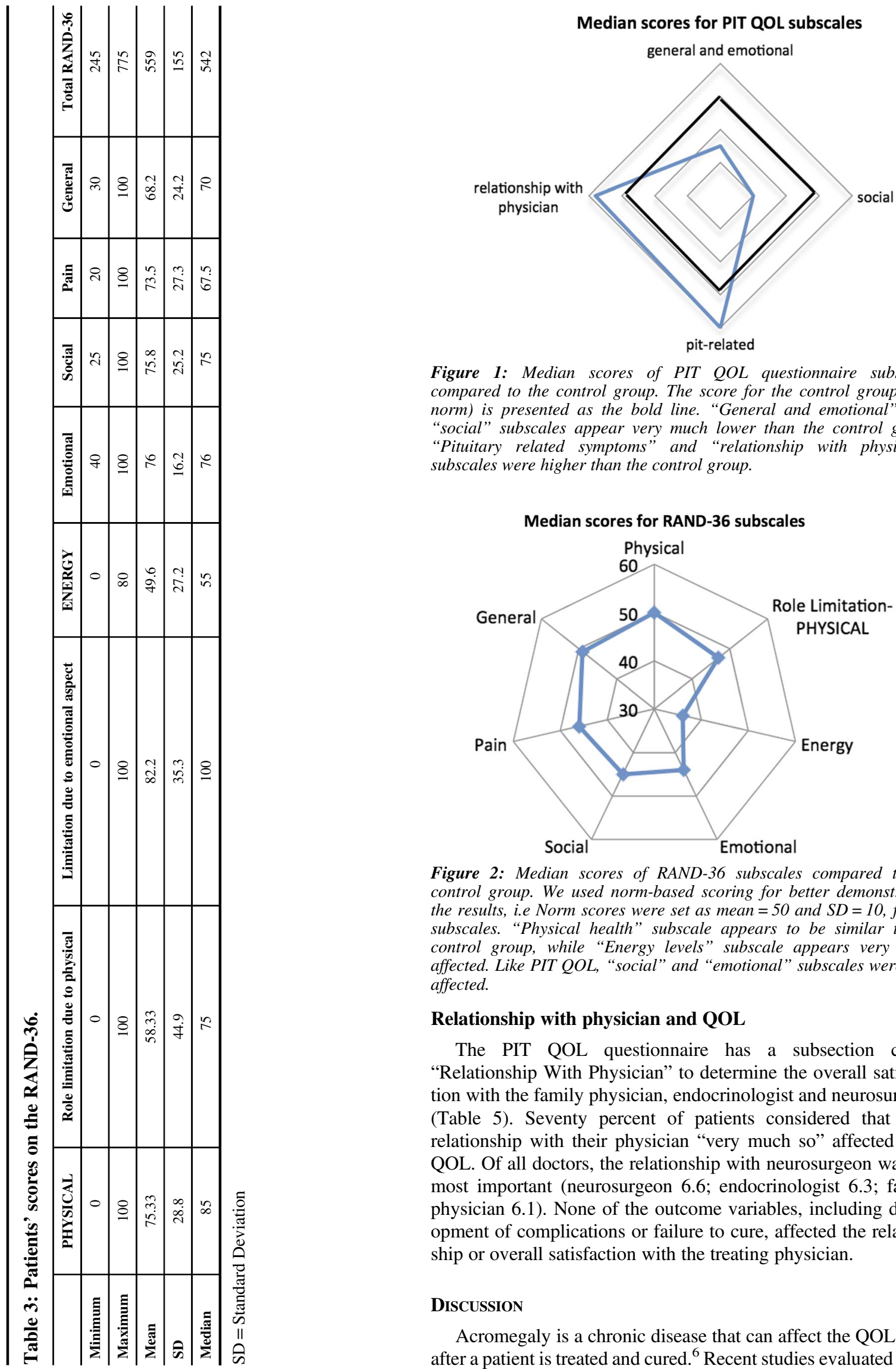

Figure 1: Median scores of PIT QOL questionnaire subscales compared to the control group. The score for the control group (The norm) is presented as the bold line. "General and emotional", and "social" subscales appear very much lower than the control group. "Pituitary related symptoms" and "relationship with physician" subscales were higher than the control group.

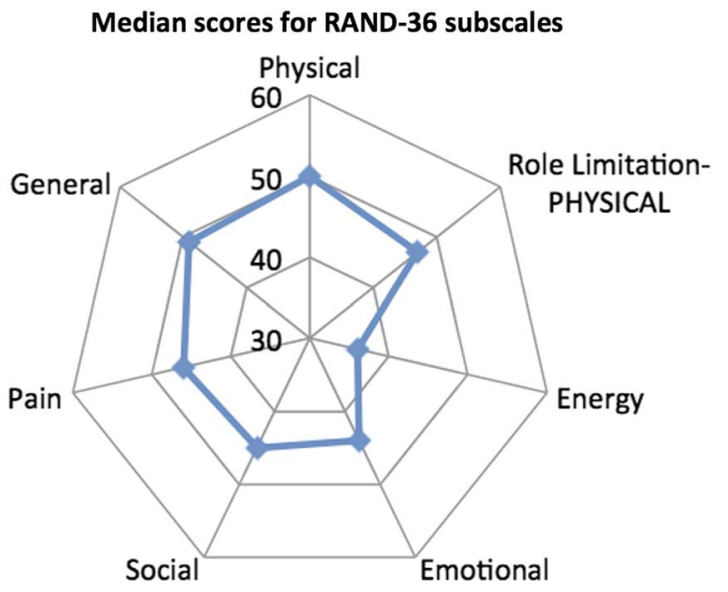

Figure 2: Median scores of RAND-36 subscales compared to the control group. We used norm-based scoring for better demonstrating the results, i.e Norm scores were set as mean $=50$ and $S D=10$, for all subscales. "Physical health" subscale appears to be similar to the control group, while "Energy levels" subscale appears very much affected. Like PIT QOL, "social" and "emotional" subscales were also affected.

\section{Relationship with physician and QOL}

The PIT QOL questionnaire has a subsection called "Relationship With Physician" to determine the overall satisfaction with the family physician, endocrinologist and neurosurgeon (Table 5). Seventy percent of patients considered that their relationship with their physician "very much so" affected their QOL. Of all doctors, the relationship with neurosurgeon was the most important (neurosurgeon 6.6; endocrinologist 6.3; family physician 6.1). None of the outcome variables, including development of complications or failure to cure, affected the relationship or overall satisfaction with the treating physician.

\section{DISCUSSION}

Acromegaly is a chronic disease that can affect the QOL even after a patient is treated and cured. ${ }^{6}$ Recent studies evaluated QOL 

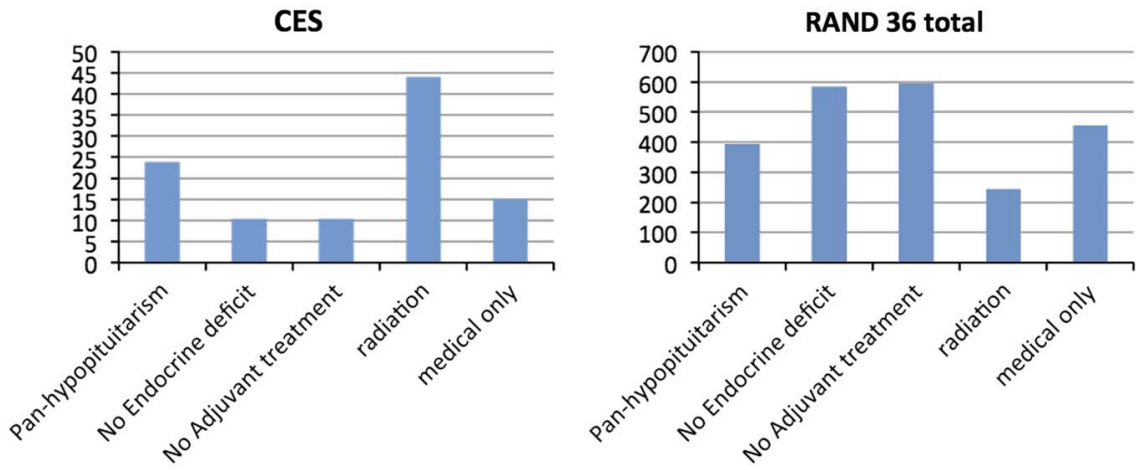

Figure 3: Effect of pan-hypopituitarism and adjuvant treatment on CES-D (left) and RAND-36 (right) scores. As discussed above, CES-D scores higher than 16 indicate depressive illness. RAND-36 scores as well, seem to be lower with pan-hypopituitarism and radiation.

Table 4: Effect of pan-hypopituitarism and adjuvant treatment on QOL scores. Other variables such as cavernous sinus invasion, remission according to the 2010 consensus, tumor volume and gross total resection had no significant effect on any of the total or subscale scores.

\begin{tabular}{l|c|c}
\hline & $\begin{array}{c}\text { Pan-hypopituitarism } \\
\text { (p Value) }\end{array}$ & $\begin{array}{c}\text { Adjuvant treatment } \\
\text { ( } \mathbf{p} \text { Value) }\end{array}$ \\
\hline Total PIT QOL & 0.30 & 0.10 \\
\hline RAND-36 SOCIAL & 0.02 & 0.03 \\
\hline RAND-36 PAIN & 0.007 & 0.05 \\
\hline RAND-36 EMOTIONAL & 0.08 & 0.02 \\
\hline RAND-36 PHYSICAL & 0.10 & 0.008 \\
\hline Total RAND-36 & 0.02 & 0.02 \\
\hline CES-D & 0.03 & 0.005 \\
\hline
\end{tabular}

PIT QOL = pituitary Quality of life; CES-D = Center for Epidemiologic Studies-Depression

for acromegaly using only one questionnaire; the "AcroQoL" questionnaire and validated its use for acromegaly. ${ }^{11-14} \mathrm{We}$ felt that this questionnaire didn't cover many aspects of HRQOL which was also confirmed by Trepp et al. ${ }^{13}$

In this study, we evaluated the QOL after ETSS for 20 acromegalic patients using the selected three questionnaires. These three questionnaires seem to complement each other as they cover almost all aspects of HRQOL, including; general, social, emotional, psychiatric, physical health, limitation due to disease, relationship with family and physician among many other factors.

Our results demonstrate that $70 \%$ of patients undergoing ETSS indicate that their general health and QOL is better compared to before surgery. The vast majority of patients enjoyed good physical health and had no limitation of activities following surgery. Contrary to what other authors have described about acromegaly, ${ }^{7-10}$ our CES-D scores of mental health indicate that most patients after surgery were free of depressive and psychological disorders.

Although $80 \%$ of our patients were satisfied by their treatment and stated that surgery improved their quality of life, our results indicate some areas that require attention in these patients. We found the social, general and emotional health (Figures 1 and 2) scores of these patients somewhat lower than expected. These aspects may be particularly neglected by most physicians. Since our patients indicated that the neurosurgeon, amongst all their doctors, plays the most significant role in their QOL, it is important that neurosurgeons be attuned to routinely address patients' social and emotional health during follow up. These patients may benefit from appropriate psychotherapeutic interventions such as behavioural therapy, support groups and participation in various social activities. One study showed that patients with an active coping style tend to feel more content and have improved QOL. ${ }^{24}$

Another aspect of QOL that was severely affected is our patients' energy levels after surgery, which is evident from the RAND-36 (ENERGY) scores (Figure 2). Lack of energy can be a trigger to social withdrawal and thus more decline in social health. Moreover, decrease in physical activity resulting from low energy levels is a precipitating factor to various cardiovascular diseases. Healthy diet and regular exercise should thus be recommended for all acromegalic patients after surgery.

An important finding of our study was that postoperative panhypopituitarism and adjuvant treatment is predictive of poor QOL scores. This is contrary to what has been reported by Trepp et al., ${ }^{13}$ however; the instruments used were different from ours. Our results could be explained by the associated symptoms of hormonal imbalance, necessity of taking life-long treatment and somatostatin analogue side-effects such as gastrointestinal upset, gall stones, pain at injection site and transient hair loss. ${ }^{25-28}$ These patients might benefit from special attention from the clinician and associated staff like social workers. Although endocrine remission and gross total resection did not significantly affect any of the QOL scores directly, these factors are important in defining the need for adjuvant therapy and so may be very important in QOL in larger series of patients. In our opinion, these results highlight the fact that surgeons should strive for resections that avoid pan-hypopituitarism and minimize the need for adjuvant therapy. These results also emphasize that our approach is feasible and that measuring QOL in addition to traditional measures outcome from neurosurgical procedures is likely to be very fruitful.

We were also able to document the very important role that the relationship between neurosurgeon and patient plays in a patient's QOL. Our results emphasize the prime role of the neurosurgeon, with $90 \%$ of our patients admitting that this relationship affected their QOL. Regardless of the patient's disease outcome, a caring approach to patients and a physician who addresses social and emotional health is likely to have patients with higher levels of 
Table 5: Relationship with physician and the effect of some factors on this relationship.

\begin{tabular}{l|c|c|c}
\hline & Family Physician & Endocrinologist & Neurosurgeon \\
\hline Overall satisfaction (score: 0-7) & & & \\
\hline Minimum score & 3 & 2 & 7 \\
\hline Maximum score & 7 & 7 & 6.6 \\
\hline Average & 6.1 & 6.3 & 7 \\
\hline Median & 7 & 7 & 0.5 \\
\hline $\begin{array}{l}\text { Effect of some outcome variables on the } \\
\text { patient-physician relationship (p VALUE) }\end{array}$ & & & 0.6 \\
\hline Endocrine remission & 0.6 & 0.4 & 0.7 \\
\hline Gross total resection & 0.5 & 0.5 & 0.7 \\
\hline Adjuvant treatment & 0.4 & 0.6 & 0.4 \\
\hline Pan-hypopituitarism & 0.5 & 0.3 & 0.1 \\
\hline Repeat surgery & 0.6 & & \\
\hline
\end{tabular}

Patients seemed to be satisfied by their relationship with all the treating physicians. As evident in this table, this relationship was not affected by failure to cure or development of complications

QOL. As evident from our results, failure to cure and development of complications didn't affect the patients' relationship with their treating physician. These findings are an important reminder to all of us that investments in the "art of medicine" are also likely to pay dividends to our patients and should be encouraged in all educational programs.

\section{LIMITATIONS}

Our study would have been improved by a larger sample size and a consistent preoperative administration of the questionnaires. Although a larger selection of questionnaires may have been useful in exploring other aspects of QOL, feasibility and participation rates may have suffered with more tedious administration of more questionnaires to patients. Our findings should be corroborated in larger multicenter and multinational studies.

\section{Conclusion}

Transphenoidal surgery improves QOL in acromegaly. Attempts to achieve a cure, avoidance of surgically induced panhypopituitarism and adjuvant therapy like radiation will improve quality of life. Our study demonstrates the important role of the patient-physician relationship to QOL and the need to measure QOL in addition to traditional measures of outcome.

\section{REFERENCES}

1. Leidy NK, Revicki DA, Geneste B. Recommendations for evaluating the validity of quality of life claims for labeling and promotion. Value Health. 1999;2(2):113-27.

2. Ware JE Jr, Sherbourne CD. The MOS 36-item short-form health survey (SF-36). I. Conceptual framework and item selection. Med Care. 1992;30(6):473-83.

3. Hays RD, Shapiro MF. An overview of generic health-related quality of life measures for HIV research. Qual Life Res. 1992; 1(2):91-7.

4. Badia X, Webb SM, Prieto L, Lara N. Acromegaly Quality of Life Questionnaire (AcroQoL). Health Qual Life Outcomes. 2004;2:13.

5. Kan P, Cusimano M. Validation of a quality-of-life questionnaire for patients with pituitary adenoma. Can J Neurol Sci. 2006;33(1):80-5.
6. Biermasz NR, van Thiel SW, Pereira AM, et al. Decreased quality of life in patients with acromegaly despite long-term cure of growth hormone excess. J Clin Endocrinol Metab. 2004; 89(11):5369-76.

7. Fava GA, Sonino N, Morphy MA. Psychosomatic view of endocrine disorders. Psychother Psychosom. 1993;59(1):20-33.

8. Flitsch J, Spitzner S, Ludecke DK. Emotional disorders in patients with different types of pituitary adenomas and factors affecting the diagnostic process. Exp Clin Endocrinol Diabetes. 2000; 108(7):480-5

9. Furman K, Ezzat S. Psychological features of acromegaly. Psychother Psychosom. 1998;67(3):147-53.

10. Pantanetti P, Sonino N, Arnaldi G, Boscaro M. Self image and quality of life in acromegaly. Pituitary. 2002;5(1):17-9.

11. Rowles SV, Prieto L, Badia X, Shalet SM, Webb SM, Trainer PJ. Quality of life (QOL) in patients with acromegaly is severely impaired: use of a novel measure of QOL: acromegaly quality of life questionnaire. J Clin Endocrinol Metab. 2005;90(6): 3337-3341.

12. Rowles S, Webb S, Lee C, Shalet S, Trainer P. Cross-sectional study of Quality of Life (QOL) in patients with acromegaly. Endocrine Abstracts. 2002;4:62.

13. Trepp R, Everts R, Stettler C, et al. Assessment of quality of life in patients with uncontrolled vs. controlled acromegaly using the Acromegaly Quality of Life Questionnaire (AcroQoL). Clin Endocrinol (Oxf). 2005;63(1):103-10.

14. Webb SM, Prieto L, Badia X, et al. Acromegaly Quality of Life Questionnaire (ACROQOL) a new health-related quality of life questionnaire for patients with acromegaly: development and psychometric properties. Clin Endocrinol (Oxf). 2002; 57(2):251-8.

15. Cusimano MD, Fenton RS. The technique for endoscopic pituitary tumor removal. Neurosurg Focus. 1996;1(1):e1; discussion following e3.

16. Giustina A, Chanson P, Bronstein MD, et al. A consensus on criteria for cure of acromegaly. J Clin Endocrinol Metab. 2010;95(7):3141-8.

17. Cusimano MD. Quality-of-Life Assessment in Patients with Lesions of the Cranial Base. Skull Base Surg. 1999;9(4):259-64.

18. Eaton W, Muntaner C, Smith C, Tien A, Ybarra M. Center for Epidemiologic Studies Depression Scale: Review and revision. In: Maruish ME, editor The Use of Psychological Testing for Treatment Planning and Outcomes Assessment, 3rd edition. Mahwah, NJ: Lawrence Erlbaum; 2004:363-77.

19. Murphy J. Symptom scales and diagnostic schedules in adult psychiatry. In: Tsuang M, Tohen M, editors. Textbook in Psychiatric Epidemiology. New York: Wiley-Liss; 2002:273-332. 
20. Naughton MJ, Wiklund I. A critical review of dimension-specific measures of health-related quality of life in cross-cultural research. Qual Life Res. 1993;2(6):397-432.

21. Radloff L, Locke B. The community mental health assessment survey and the CES-D Scale. In: Weissman M, Myers J, Ross C, editors. Community surveys of psychiatric disorders. New Brunswick, NJ: Rutgers University Press; 1986:177-89.

22. Radloff L. The CES-D scale: a self-report depression scale for research in the general population. Appl Psych Meas. 1977;1:385-401.

23. Hopman WM, Towheed T, Anastassiades T, et al. Canadian normative data for the SF-36 health survey. Canadian Multicentre Osteoporosis Study Research Group. CMAJ. 2000;163(3):265-71.

24. Bandura A. Self-efficacy: toward a unifying theory of behavioral change. Psychol Rev. 1977;84(2):191-215.
25. Chanson P, Leselbaum A, Blumberg J, Schaison G. Efficacy and tolerability of the long-acting somatostatin analog lanreotide in acromegaly. A 12-month multicenter study of 58 acromegalic patients. French Multicenter Study Group on Lanreotide in Acromegaly. Pituitary. 2000;2(4):269-76.

26. Colao A, Marzullo P, Ferone D, et al. Effectiveness and tolerability of slow release lanreotide treatment in active acromegaly. J Endocrinol Invest. 1999;22(1):40-7.

27. Giusti M, Ciccarelli E, Dallabonzana D, et al. Clinical results of longterm slow-release lanreotide treatment of acromegaly. Eur J Clin Invest. 1997;27(4):277-84.

28. Marek J, Hana V, Krsek M, Justova V, Catus F, Thomas F. Longterm treatment of acromegaly with the slow-release somatostatin analogue lanreotide. Eur J Endocrinol. 1994;131(1):20-6. 